\title{
midiätica@e
}

\section{Entre fronteiras: estéticas midiáticas na diáspora queer}

\author{
Between borders: media aesthetics in the queer diáspora
}

\author{
Hadriel Geovani da Silva THEODORO ${ }^{1}$
}

\section{Resumo}

A partir do documentário "Angel" (2010), de Sebastiano d'Ayala Valva, busca-se problematizar de que forma as estéticas midiáticas se inscrevem nas experiências de vida de migrantes LGBTIQ+ (lésbicas, gays, bissexuais, travestis, transgêneros, transexuais, intersexo, queer e outras minorias de gênero e/ou sexuais). Nesse sentido, o objetivo é averiguar a construção de estéticas midiáticas na/da diáspora queer. Os procedimentos metodológicos estabelecidos articulam uma reflexão teórica sobre a temática com uma análise audiovisual do referido documentário (descritivo-analítica). Como principais apontamentos, destaca-se o viés político do que se pode considerar queer-estéticas e os processos de exclusão que a tomam como fundamento.

Palavras-chave: Diáspora queer. Imigração LGBTIQ+. Estética. Mídia.

\begin{abstract}
From the documentary "Angel" (2010), by Sebastiano d'Ayala Valva, we try to problematize how the mediatic aesthetics are inscribed in the life experiences of LGBTIQ+ migrants (lesbians, gays, bisexuals, transvestites, transgenders, transsexuals, queer and other gender and/or sexual minorities). In this sense, the objective is to investigate the construction of media aesthetics in the/about the queer diaspora. The methodological procedures established articulate a theoretical reflection on the subject with an audiovisual analysis of the documentary (descriptive-analytical). As the main notes, the political bias of what can be considered queer-aesthetics and the exclusion processes that take it as a foundation is highlighted.
\end{abstract}

Keywords: Queer diáspora. Immigration LGBTIQ+. Aesthetics. Media.

\section{Introdução}

Os movimentos migratórios sempre estiveram inscritos na história da humanidade. No entanto, o entendimento que se tem sobre eles permaneceu

\footnotetext{
${ }^{1}$ Doutorando da Escola Superior de Propaganda e Marketing (ESPM-SP). Bolsista FAPESP.

E-mail: hgtheodoro@gmail.com
}

Ano XI, n. 21 - jul-dez/2018 - ISSN 1983-5930 - http://periodicos.ufpb.br/ojs2/index.php/cm 


\section{midiäticales}

profundamente orientado por valores tradicionais e patriarcais, destacando em seu cerne a importância da figura masculina (ALENCAR-RODRIGUES; STREY; ESPINOSA, 2009). Ao se tomar a trajetória dos homens migrantes como sendo uma norma, houve (e ainda continua a haver) um ocultamento da presença das mulheres como integrantes centrais nesse contexto (KRZESLO, 2007).

Com base em tal hierarquia de gênero, que aloca o masculino e tudo que a ele se relaciona em um patamar de maior valor, ocorre um processo de invisibilização das mulheres, que se reflete inclusive nos estudos e pesquisas acadêmicas acerca da temática. A produção científica sobre as questões de gênero englobadas nos movimentos migratórios, por exemplo, começou a se desenvolver nos Estados Unidos apenas na década de 1980; no Brasil, dez anos mais tarde (KOSMINSKY, 2004). E essa invisibilidade não está contida apenas no apagamento das mulheres enquanto partícipes do fenômeno, mas igualmente na representação de caráter coadjuvante que comumente recai sobre elas (ALENCAR-RODRIGUES; STREY; ESPINOSA, 2009). Negligenciando o fato de que as experiências migratórias de mulheres e homens são vivenciadas de modos distintos, silenciam-se as vozes das mulheres migrantes e consequentemente se debilitam suas representações socioculturais. De acordo com Krzeslo (2007), trata-se de um olhar obsoleto sobre os deslocamentos humanos, que, graças aos esforços de pesquisas inspiradas pelos movimentos feministas (também a partir da década de 1980), vem sendo questionado e problematizado.

A apreensão dos limites das reflexões a respeito das questões de gênero nos fluxos migratórios auxilia a melhor compreender as múltiplas camadas de silenciamento e invisibilidade quando nos voltamos às particularidades abarcadas nas experiências de migrantes LGBTIQ+ (lésbicas, gays, bissexuais, travestis, transgêneros, transexuais, intersexo, queer e outras minorias sexuais e/ou de gênero). Desde o momento inicial da estruturação da pesquisa de doutorado que venho desenvolvendo ${ }^{2}$, ficou patente a dificuldade de encontrar dados e informações sobre o assunto; isso em diferentes esferas: midiática, acadêmica, institucional, estatal e jurídica. Assim como no caso das mulheres migrantes, tal exclusão não apenas indica a presença de assimetrias e

\footnotetext{
2 Intitulada "(In)visibilidades sociocomunicacionais nas vivências de imigrantes e refugiadas/os LGBTIQ+ na cidade de São Paulo", realizada no Programa de Pós-Graduação em Comunicação e Práticas de Consumo da Escola Superior de Propaganda e Marketing de São Paulo, orientada pela Prof. ${ }^{\text {a }}$ Dr. ${ }^{a}$ Denise Cogo e com financiamento da Fundação de Amparo à Pesquisa do Estado de São Paulo (FAPESP).
} 


\section{midiäticale}

desigualdades, mas aponta para uma de suas consequências mais nefastas: a vulnerabilidade e precarização da vida de migrantes LGBTIQ+.

Estamos diante do que se pode nomear de diáspora queer. A concepção de diáspora se ancora em uma definição dicotômica de diferença: fundamenta-se em uma zona de exclusão e, ao mesmo tempo, submete-se à construção de um "Outro", que demarca posições estritas entre o dentro e o fora, entre o que pertence e o que deixa de fazer parte (HALL, 2013). Queer, por sua vez, está intimamente vinculado à noção de abjeção, que diz respeito às vidas que não são lidas como "vivenciáveis" e cuja materialidade deixa de ser apreendida como válida, como humana (BUTLER, 2011). Esse lócus menos-que-humano se arraiga indireta ou diretamente nas experiências de vida de sujeitos LGBTIQ+, sendo que preconceitos, discriminações, violências simbólicas e/ou físicas são gatilhos à diáspora queer. Não nos esqueçamos que ainda hoje mais de 70 países continuam a criminalizar de algum modo sujeitos LGBTIQ+, com punições que variam de açoitamento público à pena de morte. ${ }^{3}$

Segundo Wesling (2008), a diáspora queer se refere a um processo histórico de longa data, mas que se intensifica com a globalização. Sendo assim, é preciso considerar que, se por um lado ela fomenta cada vez mais um fluxo de bens, capitais, informações e pessoas, por outro ela esconde uma verdadeira geografia de exclusões, pois nem toda/o migrante tem resguardada sua cidadania e seus direitos mais básicos, inclusive o de se deslocar livremente. Na diáspora queer, por exemplo, há uma dupla desestabilização que a impacta de forma axiomática: o queer subverte a normatividade de gênero e sexual, enquanto a diáspora de sujeitos LGBTIQ+ influi sobre uma suposta estabilidade nacional e geográfica (WESLING, 2008). Daí a importância de se analisar as dinâmicas de (in)visibilidade sociocomunicacionais engendradas nos fluxos migratórios, pois elas nos permitem verificar como sua diversidade é transposta às representações das vivências de quem migra. Logo, não há mais espaço para se entender os fluxos migratórios como uma massa amorfa, hegemonicamente masculina, heterossexual e cisgênera ${ }^{4}$.

\footnotetext{
${ }^{3}$ Como exemplo: "Relação homossexual é crime em 73 países; 13 preveem pena de morte". Disponível em: $\quad$ http://g1.globo.com/mundo/noticia/2016/06/relacao-homossexual-e-crime-em-73-paises-13preveem-pena-de-morte.html>. Acesso em: mar. 2018.

${ }^{4}$ Cisgeneridade corresponde à identificação com o gênero designado ao nascer.
} 


\section{midiäticale}

A relevância das mídias nas interações interpessoais, representações de mundo e construções identitárias é, nesse sentido, inegável. Elas perpassam a tessitura da vida cotidiana, (re)compondo em permanência suas dimensões estruturais (SILVERSTONE, 2005). Sem deixar de levar em conta o encadeamento intrínseco entre o tecnológico e o social, há de se notar o quanto somos dependentes da oferta pública de significados sobre os acontecimentos em nosso tempo: tais significados se ensejam especialmente nas e pelas mídias (SILVERSTONE, 2010). Na ordem global, destaca-se o desempenho infotemporal e tecno-organizacional das mídias, constantemente orbitando as tecnologias da informação e da comunicação (TICs) e as sociabilidades que elas facultam, das quais seu desenvolvimento depende (ELHAJJI, 2006). Na intrincada convergência desse encontro - entre tecnologia, cultura e sociedade - engendram-se novos âmbitos de produção de subjetividades, discursividades e, por conseguinte, singularidades (ELHAJJI, 2006).

Também não podemos desconsiderar a dimensão estética abarcada. Desde Walter Benjamin (1987) parece ter ficado claro que em qualquer meio de comunicação está implicada uma experiência do sensível (ou o sensório, nas palavras do autor). Rancière (2009), por sua vez, não dissocia a estética, em seus aspectos afetivos e cognitivos, da política, a salientar sua relevância no processo de apreensão e leitura do mundo. Diante de um contínuo esfacelamento das fronteiras entre as formas de arte e a vida em si, a estética deixa de estar restrita somente a seu viés artístico e emerge enquanto experiência estética na cotidianidade, onde entremeia os processos de deslocamento nos atuais fluxos migratórios, sobretudo por meio da mediação das mídias.

Tendo isso em mente, a problemática proposta neste artigo pode ser sintetizada da seguinte maneira: como estéticas midiáticas se inscrevem nas experiências de migrantes LGBTIQ+ e em suas representações sociocomunicacionais? A partir dela, o objetivo é justamente analisar a (des)construção de estéticas midiáticas na/da diáspora queer e refletir acerca de seus impactos nos projetos migratórios de sujeitos LGBTIQ+. Para tanto, tomo como substrato empírico à analítica o documentário “Angel” (2010), de Sebastiano d'Ayala Valva. 


\section{midiática@ę)}

\section{Percurso metodológico}

Meu primeiro contato com a história de Angel se deu através do documentário "Les travestis pleurent aussi” (“As travestis também choram”, 2006), igualmente realizado por Sebastiano d'Ayala Valva. Nele, somos apresentados a uma travesti, prostituta, negra e imigrante não regularizada residindo em Paris. Angel é constantemente impelida às margens da sociedade e exotizada por seus atributos físicos, ao mesmo tempo em que, sob o manto da noite, é requisitada em um mercado sexual de prazeres. Dado que as histórias individuais de migrantes, em suas subjetividades e vivências particulares, têm de ser levadas em consideração nos estudos migratórios, Angel, uma das figuras centrais do documentário, expõe por meio dessa produção midiática uma realidade de exploração, preconceitos, discriminações e vulnerabilidades que experiencia no dia a dia.

Quatro anos depois, Angel, também conhecida como "La Mujeron", volta a ser tema de uma produção cinematográfica documental, no filme que leva seu nome. Após conseguir obter uma "carte de séjour", tipo de visto que lhe autoriza finalmente deixar a França tendo a garantia da possibilidade de retorno, Angel decide visitar sua família no Equador. Sebastiano a acompanha nessa jornada.

Haja vista a escassez de produções midiáticas que buscam representar as vivências de sujeitos LGBTIQ+ migrantes, a escolha por analisar o documentário “Angel” se revela privilegiada. Isso porque nos permite problematizar a questão da diáspora queer, desde um ponto de vista mais próximo das vivências desses sujeitos. Concomitantemente, viabiliza uma reflexão sobre o modo como as estéticas midiáticas aí englobadas influenciam em suas vivências e em nosso olhar sobre esse "Outro".

Para desenvolver a análise proposta, parto de uma teorização acerca das representações do queer no cinema e as principais características do documentário “Angel”. Em seguida, empreendo uma descrição da narrativa documental do filme, com o intuito de destacar os principais pontos relacionados à problemática. Por fim, valendome dessa descrição, desenvolvo uma análise crítica das estéticas midiáticas nele contidas e a forma como se associam mais amplamente às vivências de sujeitos LGBTIQ+. 


\section{midiätica@e}

\section{Da estética ao cinematográfico, dos fluxos migratórios ao queer}

A experiência dos sujeitos na contemporaneidade está intensamente pautada por uma dimensão estética. Deixando o domínio circunscrito da arte e sendo potencializada pelo sistema capitalista, ela opera um regime de sensibilidade, de verdade e de visibilidade, "em que a vida e as imagens, em sua plasticidade e capacidade de invenção, tanto escapam às dominações quanto demandam ser por elas reativadas" (FELDMAN, 2008, p. 61). Tal regime, é válido pontuar, não está isento de conflitos; ao contrário, é marcado por paradoxos e inconformidades. A experimentação estética do mundo, paulatinamente no decorrer da modernidade, transmuta-se no motor da experiência urbana e da vida cotidiana, em seus processos individuais e sociais de produção, circulação, consumo e regulação (FELDMAN, 2008).

Com o espraiamento da esfera midiática, graças às constantes evoluções das TICs, a realidade passa a ser inegavelmente mediada por suportes audiovisuais e seus códigos estéticos - ao nível mesmo de saturação (BRASIL, 2006). Contudo, como assevera Feldman (2008, p. 62):

(...) cada vez mais a mediação realizada pelas tecnologias da comunicação, da informação e do audiovisual deixa de ser propriamente um ato ou efeito de mediar, de estabelecer relações, para tornar-se, ela mesma, parte crucial de nossa visão de mundo e daquilo que tomamos por realidade, a qual é percebida e construída por códigos estéticos historicamente configurados, balizadores de nosso olhar e de nossa experiência.

Além disso, temos de depreender que a realidade é estruturada por meio de narrativas que dão sentido à experiência, cujos efeitos concretos se refletem em nossa subjetividade. Esta, por sua vez, está alicerçada em uma extensa cadeia de imaginários audiovisuais, condicionados por políticas de fala e de visibilidade. É nesse sentido que se faz necessária a compreensão de que as produções cinematográficas - tidas como a "sétima arte" - inscrevem-se como geradoras de representações sociais. O problema reside, porém, no fato de que essas representações podem ser prejudiciais a determinados grupos, como é o caso dos sujeitos LGBTIQ+. Isso porque nem toda forma de visibilidade é em si positiva a eles (THEODORO, 2016). 


\section{midiäticales}

Lopes (2006), por exemplo, sublinha o fato de que é extremamente recente a preocupação - para longe de ser disposta apenas como temática - com as questões sexuais e de gênero nas obras de arte e produções culturais (remontam à década de 1970). O que se torna patente é a premência de uma diversidade de narrativas no texto da cultura, onde uma estética híbrida, intertextual, transemiótica e multimidiática é imprescindível. No âmago dessa perspectiva heterogênea, a identidade se desprende de sua perspectiva lógica, formal e filosófica para dar espaço também ao seu caráter histórico, social e político, o que permite uma politização da experiência privada de sujeitos reiteradamente impelidos às margens, fora dos marcos limítrofes do considerado “aceitável” (LOPES, 2006).

Busca-se, então, alternativas estéticas que facultem uma representação múltipla da diferença e daqueles sujeitos que sãos alocados além de suas fronteiras, como os LGBTIQ+. Obviamente não há como desprezar nem as dinâmicas de mercado que regem o cinema (ou, de modo mais amplo, as “indústrias culturais"), tampouco os movimentos sociais que lutam diariamente para modificar a precariedade da existência dos sujeitos tidos como abjetos. Mas, de qualquer forma, o engajamento político, as dissidências e as margens estão se fazendo cada vez mais presentes nesses espaços midiáticos. Como consequência, precisamos desenvolver um olhar crítico acerca dos discursos identitários da diferença, tanto no cinema contemporâneo quanto em todas as produções midiáticas nos seus mais distintos meios e formatos.

Acresce-se a isso mais um nível de complexidade: a representação midiática dos fluxos migratórios. Quando abordamos o tema, não é incomum vir à mente imagens amplamente difundidas da migração massiva de pessoas devido a guerras, perseguição política, pobreza, desastres naturais, etc., como no caso da crise humanitária de alguns países africanos e da Síria - quem não se recorda da imagem de Aylan Kurdi, inerte e sem vida, na areia da praia? As identidades nacionais desempenham nesse contexto um importante papel enquanto instrumento político nas relações geopolíticas internacionais (PRYSTHON, 2009). Na década de 1960, por exemplo, o Terceiro Cinema intenta quebrar a ordenação desigual de tais estéticas geopolíticas, por meio da inserção de sujeitos excluídos no foco de suas produções, uma rebeldia estética que equivale a uma rebeldia política e de ação social. O descentramento decorrente reverbera por todo o plano cultural, redimensionando o papel da periferia, das margens e do "terceiro 


\section{midiätica@ \\ REVISTA DO PROGRAMA DE \\ PÓS-GRADUAÇÄO EM COMUNICAÇ̃O DA \\ UNIVERSIDADE FEDERAL DA PARAIBAA}

mundo", a consolidar e legitimar estéticas cinematográficas alternativas (PRYSTHON, 2009). A difusão da Internet e o barateamento das TICs vão ser seus potencializadores.

Como no caso do documentário "Angel” todos os aspectos mencionados até aqui estão transpassados por uma narrativa biográfica, também precisamos considerá-lo enquanto um registro, um arquivo que guarda em si sentidos de representações sobre a diáspora queer. Nesse sentido, Arantes (2015) aponta como o passado é primordial às nossas experiências e às significações que estabelecemos para com a realidade vivenciada. Tomando como base o conceito de arquivo, a autora desperta a atenção para o fato de que a dimensão do tempo, fundamentada em uma seleção ou recorte efetuado pela memória, é politizada. Ou seja, no campo das representações, ocorre uma politização da memória (ARANTES, 2015). Quebra-se, portanto, qualquer fixidez que se intente condicionar a ela: a memória se enseja em um fluxo de (re)construções permanentes. É a partir desse entendimento que podemos compreender que a história não deve ser tomada como linear, mas, sim, construída por uma multiplicidade de lembranças e esquecimentos sempre em jogo - um jogo político e de poder.

Daí a relevância de contar aquilo que normalmente não é contado. Valendo-se de Derrida, para o qual o conceito de arquivo diz respeito não a um conjunto de documentos, mas, pelo contrário, a uma operação, a um dispositivo performativo aberto, Arantes (2015) afirma o valor inestimável de uma grafia da história entendida como apresentação, passível de contestação e outros significados: uma ininterrupta relescritura.

Essas reflexões são significativas ao sublinhar o intrincado processo que a representação e a interpretação midiáticas a respeito do fenômeno da mobilidade humana congregam. Nele, é evidente o conflito como um eixo central das narrativas. Um cinema voltado ao viés diaspórico e transcultural tem de conter em seu interior uma política de resistências, para que não recaia sobre a/o migrante uma carga simbólica potencialmente negativa, que congloba, ademais de prejuízos de valor, a "culpa" pela desterritorialização, seja no cinema mainstream ou alternativo (TEIXEIRA, 2016). Trata-se de um esforço de ordem epistêmica, para que haja a criação de novos valores estético-discursivos capazes de retratar as desigualdades inerentes aos fluxos migratórios e à diáspora queer e o entrecruzamento de fronteiras - entendendo-as aqui como variáveis correlatas a marcadores sociais de diferença. 


\section{midiática@ę)}

\section{O périplo de um anjo}

Embora a narrativa documental de "Angel" se desenvolva de maneira cronológica, existe uma série de "cortes" que correspondem às mudanças espaçotemporais que Angel efetua ao longo de seu périplo. Em razão disso, realizo uma descrição por cenas, selecionando aquelas que considero mais relevantes à problemática

estabelecida. É pertinente assinalar que, apesar de o documentário estar disponível de forma pública no site de compartilhamento de vídeos YouTube, opto por não reproduzir neste artigo nenhuma de suas imagens. O motivo principal dessa escolha é não me apropriar indevidamente da imagem de Angel (de qualquer modo, deixo o convite para que a/o leitora/leitor o assista, se ainda não o fez).

Consequentemente, enfatizo inúmeras vezes as características corporais de Angel e a forma como ela se veste, para compor um quadro das expressões de gênero por ela exprimidas (o que explica também a adjetivação empregada). Como abordarei adiante, essa perspectiva de análise é relevante uma vez que o corpo e os suportes que nele se externam podem ser considerados mídias (BAITELLO, 2010).

Cena 1: Em face ao Moulin Rouge, Angel apresenta o bairro em que vive. Além de destacar o ponto turístico da capital francesa, também mostra um lugar bastante específico: o estabelecimento onde realiza as transações financeiras para enviar dinheiro à família. Em seguida, é a vez de sua irmã, Blasina, gravar uma mensagem, dirigindo-se aos filhos que deixou no Equador.

Cena 2: Após a abertura do documentário, aparece em tela cheia a foto de um homem jovem, musculoso, vestindo calça e camiseta. Este é Angel antes de passar a se travestir para se prostituir nas ruas de Paris. O contraste se evidencia quando a vemos sair de seu pequeno apartamento com destino ao seu local de trabalho. Está maquiada, usa uma minissaia rosa apertada, destacando os contornos das pernas torneadas, uma espécie de espartilho que realça os seios fartos, sapatos de salto e uma peruca de cabelos negros e lisos, na altura dos ombros. Toma um táxi e logo se dirige à região do Bois de Boulogne, conhecido ponto de prostituição.

Cena 3: Angel se encontra no aeroporto, despedindo-se de sua irmã e de uma amiga. Está embarcando ao Equador. (A partir desse ponto, o documentário focaliza os inúmeros encontros e desencontros no retorno de Angel à sua terra natal). 


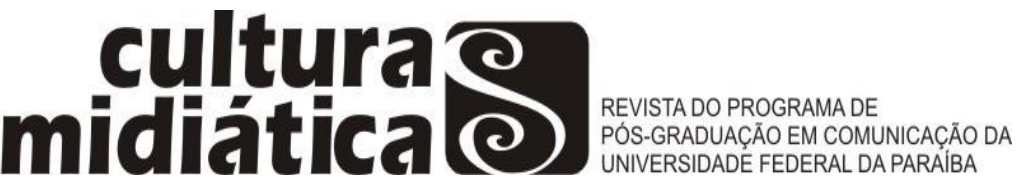

Cena 4: Em Guayaquil, Angel se distancia do centro da cidade. É rumo à periferia pobre que ela parte. As ruas pavimentadas dão lugar ao chão batido e as grandes avenidas com monumentos a casas simples e inacabadas. Em uma delas, mora sua mãe.

Cena 5: O reencontro com os familiares é visivelmente marcado por laços de afetos; mas o que se notabiliza é o ato de presentear. Angel traz consigo várias bagagens contendo souvenirs aos familiares, que logo se reúnem na casa de sua mãe. Perucas, sapatos, roupas e DVDs estão entre os itens trazidos por Angel para presenteá-los.

Cena 6: Há um espanto geral em relação ao corpo de Angel. Uma de suas primas lhe apalpa as maçãs do rosto, perguntando o que ela fez com elas e opinando que agora está mais feia que antes. Uma de suas irmãs, ao vê-la, logo afirma que a agora Angel tem mais seio que "uma mulher".

Cena 7: Angel mostra à sua família uma foto sua na Marche des Fiertés de Paris (ou Gay Pride de Paris). Ela abraça um homem no meio de uma multidão de pessoas. Está vestida inteiramente de vermelho, com uma calça justa e uma camiseta regata. Também está usando uma peruca curta e um pouco de maquiagem. Em outra foto, aparece completamente travestida na ocasião de um aniversário: porta uma camisa preta com decote, uma peruca longa de cabelos claros e encaracolados e maquiagem, com destaque à sombra azul nos olhos e os lábios de um vermelho intenso. Angel expõe as fotos para todos os familiares presentes, incluindo as crianças.

Cena 8: Depois de se instalar, Angel sai para passear no bairro e rever alguns conhecidos. Está usando uma calça jeans apertada, uma blusa de estampa com decote, uma peruca curta na cabeça e uma bolsa lateral. É cercada por crianças que lhe dirigem palavras de baixo calão, buscando ofendê-la. Também é possível escutar assobios de assédio por onde passa.

Cena 9: Angel vai a uma espécie de balneário, chamado Salitre. Nessa ocasião está vestindo um maiô, uma touca na cabeça e um short na altura do joelho. Tanto no transporte público que utiliza para chegar lá quanto nos momentos em que passeia pelo balneário, Angel é o centro das atenções. Mulheres pedem para apalpar seus seios, homens a olham de revés, crianças parecem impressionadas com sua presença.

Cena 10: De volta ao cotidiano na casa de sua mãe, Angel logo assume uma centralidade no lar, principalmente na sua organização e limpeza, o que chega a causar incômodo em alguns de seus familiares. No espaço privado da casa, Angel segue se 


\section{midiäticales}

vestindo com roupas "femininas", apesar de não usar peruca nem maquiagem. Alguns de seus familiares destacam a importância de Angel em suas vidas. Um de seus irmãos, por exemplo, revela que conseguiu realizar uma formação de policial graças à ajuda financeira dela recebida.

Cena 11: Angel visita a academia de boxe onde praticava o esporte na juventude. Apesar de estar vestida com uma calça larga e uma jaqueta de frio, não deixa de esconder a blusa tomara que caia que usa por baixo. Pouco tempo depois, Angel aparece sem o casaco, e seus seios ficam em evidência. Os antigos colegas e treinadores não deixam de reparar nas mudanças corporais pelas quais passou. Nesse momento, várias fotos antigas de Angel são mostradas: ela está no ringue, em combate, e se evidencia seu corpo extremamente forte e musculoso.

Cena 12: Angel visita algumas amigas travestis em Quito, local onde foi morar depois de sair de casa quando jovem. Uma delas conta que Angel não gostava de trabalhar na prostituição na cidade, pois tinha muitos problemas com os policiais, que geralmente não respeitavam pessoas LGBTIQ+ (muitas/os de suas/seus amigas/os morreram assassinadas/os nas mãos de policiais; outras/os eram jogadas/os no rio Machangara).

Cena 13: Alexis Ponce, diretor de Asamblea Permanente de Derechos Humanos del Ecuador (APDH) e cofundador do primeiro movimento trans no país, chamado Coccinelli, faz um relato sobre a importância de Angel ao movimento LGBTIQ+ de Quito. Ele afirma que, por ser conhecida como ex-boxeadora, era respeitada e temida, até mesmo por policiais. Além disso, segundo Ponce, Angel se valia desse respeito e temor como arma para defender suas/seus companheiras/os.

Cena 14: Paris, um ano depois. Angel se prepara para mais uma noite de prostituição. Blusa vermelha com decote, minissaia justa, bijuterias, peruca de cabelos lisos na altura dos ombros, maquiagem forte destacando os contornos do rosto.

\section{Sobre queer-estéticas}

Vivemos um inegável império da visualidade, em que a imagem adquire uma primazia na mediação da realidade experienciada. Muitas vezes, o imagético passa inclusive a assumir uma (pretensa) correspondência direta com tal realidade, como se a refletisse integralmente - o que Feldman (2008) intitula de "apelo realista". Sendo 


\section{midiäticales}

assim, é importante compreender que nossas corporalidades também estão inscritas nesse domínio do visual, e que ele é regido por códigos estéticos bastante rígidos.

As normatizações estéticas dos corpos são socioculturalmente estruturadas e midiaticamente fomentadas, difundidas, compartilhadas e (re)significadas. Ao entrecruzá-las com o gênero, podemos observar como servem à sustentação ou desestabilização de seus binarismos, sobretudo no que diz respeito à legibilidade social. É uma conformação estética a primeira fronteira que nos separa em dois grupos incongruentes: o órgão que esteticamente se adequa ao entendimento do que seja uma vagina confere a seu portador (ainda na maternidade, ou antes disso) uma carga generificante que vai da estruturalidade do discurso - o modo como se nomeará esse sujeito - à materialidade de sua existência, condicionando-o à redoma da feminilidade antes mesmo que tenha a oportunidade de desenvolver uma consciência própria sobre sua identidade e expressão de gênero; no sentido oposto, o mesmo sucede com a imagética de um pênis, signo fálico assentado no núcleo de uma masculinidade hegemônica.

Em suma, temos uma codificação estética da feminilidade e da masculinidade que influi diretamente no modo como determinada sociedade e cultura entende o "ser mulher" ou "ser homem" e todo seu regime disciplinar. Como bem assinala Preciado (2008), o gênero não se trata de uma simples derivação do sexo anatômico ou biológico, mas, sim, de uma construção, "de um efeito do cruzamento de representações discursivas e visuais que emanam de diferentes dispositivos institucionais (...)" (PRECIADO, 2008: 98, tradução e grifos do autor).

Considero oportuna, nesse sentido, a teorização Harry Pross acerca da mídia, pois, estendendo um conceito que geralmente fica condicionado aos meios tecnológicos de comunicação, passa a englobar as corporalidades (o que nomeia de mídia primária) e os suportes que nelas se exteriorizam (mídia secundária) (BAITELLO, 2010). Ou seja, viabiliza-se a apreensão do corpo, em suas cores, odores, formas e gestos como uma mídia com forte capacidade comunicacional. Isso significa que o corpo, em suas visualidades, não apenas abarca uma dimensão estética, mas a comunica em permanência. Por outro lado, o corpo, em suas imagéticas, in-forma, haja vista que "ao recuperar sua potência estética (e política), a imagem torna-se centrífuga, nos desloca para fora dela mesma, para além do sentido que nela estaria imediatamente visível" (BRASIL, 2006, p. 96). 


\section{midiäticales}

No caso de Angel, essa interface midiática das corporalidades fica patente. Ao romper uma estética hegemônica tanto da masculinidade quanto da feminilidade, ela se converte em uma imagética dissidente dos marcos binários do gênero. Mas isso não ocorre sem que haja uma repressão de tal "transgressão". Por diversas vezes ao longo do documentário (como descrito nas cenas 6 e 9), seus seios advêm o centro de um questionamento contínuo acerca de sua imagem. Por mais que, nas cenas em questão, os seios despertem mais uma curiosidade por parte de outras mulheres - inclusive membros de sua família -, eles não deixam de causar estranhamentos. Estes ocorrem justamente pela quebra paradigmática de uma normatização regulatória do gênero e, ao mesmo tempo, de uma ditadura estética generificada dos corpos. Não é incomum que se espere de pessoas transgêneras que, ao cruzar o limiar do gênero que lhes foi designado ao nascer, correspondam ao menos visualmente ao padrão do gênero oposto, adequando-se a uma conformação binária (THEODORO, 2016). Quanto mais se enquadra ao seu ditame estético, mais fácil se torna sua passabilidade (isto é, quando uma pessoa transgênera é socialmente lida como cisgênera).

De certa forma, essa desestabilização é trazida ao interior do documentário e por ele problematizada. Como evidenciado nas cenas 2 e 12, em alguns momentos fotos antigas de Angel são exibidas, estabelecendo um contraponto entre suas expressões de gênero antes e depois da migração à França e o decorrente travestimento (ou, de forma mais ampla, o processo de transgenerificação). O que emerge é uma hibridez estética que borra as fronteiras da feminilidade e da masculinidade em um corpo em constante transformação.

Apesar de acarretar a Angel uma inquestionável precarização de sua existência (expressa, por exemplo, na cena 8), tal hibridez também possui uma potencialidade política, que questiona a mesma dicotomia de gênero e a hegemonia estética que a corrobora: as cenas 6, 7, 8, 9, 10, 11 e 14 justificam tal apreensão, ao demonstrar que Angel ocupa frequentemente um locus in between, ou seja, um ponto intermediário que tensiona as bases ordenatórias de seus princípios regimentais.

Podemos nos voltar aqui ao relato de Alexis Ponce (cena 13): é por meio de uma transestética que Angel, em suas corporalidades, enfrenta preconceitos, discriminações e violências policiais. A feminilidade que manifesta não anula o poderio de uma virilidade expressa em um corpo forte e musculoso (e vice-versa). Essa femasculinidade ou masfeminilidade demonstra que, "transversal, a experiência estética atravessa e é 


\section{midiäticales}

atravessada pela experiência ordinária, provocando nela um estremecimento (...)" (BRASIL, 2006, p. 96).

Por outro lado, em um movimento cíclico que une o início e o final do documentário, observamos (vide cenas 2 e 14) como essa mesma hibridez é acionada em um mercado sexual como capital de permuta de prazeres. As características físicas de Angel e as queer-estéticas nelas contidas se convertem em uma propriedade de consumo, cujo valor de troca se dá precisamente no rompimento de limites do que socioculturalmente se sanciona ao feminino e ao masculino, bem como em suas representações visuais e estéticas. As singularidades de seus traços - uma travesti, negra, imigrante, latina - são transpostos em um corpo-mercadoria, onde a exotização e a fetichização se articulam como moeda no sentido de uma garantia de ganhos financeiros.

É a partir dessas trocas que Angel consegue dinheiro para sustentar a si e à família no Equador. Toda uma rede de afetos, de relações familiares e de cuidado (como quando, logo na cena 1 , nos apresenta o lugar que serve para enviar dinheiro à família, em um contraponto direto ao ponto turístico Moulin Rouge, como se evidenciasse sua importância) depende, por conseguinte, dos atrativos provenientes das transcorporalidades de Angel. É interessante notar aqui o papel que em geral se condiciona ao feminino nas migrações transnacionais: o encargo do núcleo familiar (KRZESLO, 2007), função que Angel (assim como sua irmã, Blasina) indubitavelmente desempenha - a partir de sua prostituição (como na cena 10, quando fica claro que as remessas de dinheiro enviadas por Angel ultrapassam a subsistência da família).

Podemos constatar, assim, o quão intrincado é o regime de visibilidade que se entremeia nas queer-estéticas, por excelência (bio)políticas. Se a ela temos acesso por meio de uma mediação midiática - a produção, veiculação e consumo do documentário “Angel” -, há de se considerar que, ao mesmo tempo, dizem respeito às experiências concretas de um sujeito, que sente na própria pele os efeitos mais perversos da não adequação à heterocisnormatividade (BUTLER, 2008). Isso porque seus códigos estéticos usualmente estão assentados além da fronteira, no território ininteligível da diferença que exclui, que violenta, que extermina. Quantas outras Angel's não existem? 


\section{midiática@ę)}

\section{Considerações finais}

Com base na análise efetuada, penso haver dois apontamentos centrais a realizar. O primeiro deles corresponde ao documentário enquanto produção audiovisual. Nesse sentido, parece ser muito proveitoso o modo como nos conduz pelas experiências de Angel, em seus deslocamentos transnacionais, em suas vivências de travesti, prostituta, negra, latina, pobre. Sem negligenciar a multiplicidade de leituras viáveis no processo de recepção comunicacional, acredito que sua estética midiática contribui àquilo que Teixeira (2016) designa por "formação de um olhar", capaz de ver - e talvez de problematizar - o que costuma permanecer sob uma invisibilidade forçada, que serve como arma de exclusão de minorias representativas, como o caso de sujeitos LGBTIQ+ e, sobretudo, de sujeitos LGBTIQ+ migrantes. Em um contexto em que esses sujeitos são reiteradamente silenciados e invisibilizados ou têm sua representatividade essencializada, a dimensão estética da resistência contida no documentário faculta uma expressão das condições migratórias por eles vivenciadas.

A narrativa construída com as e pelas experiências de Angel assinala uma margem da estética (PRYSTHON, 2009), que, ao infringir estruturas cinematográficas hegemônicas, favorece uma representação política mais plural. Ferreira (2010) assevera que pode haver nesse tipo de produção o fomento a uma cultura das bordas, cujas camadas de imaginários, consumos, especificidades de viver e de poder expressar(se) fora dos sistemas centrais propicia uma maior diversidade nos espaços da cultura e consequente visibilidade do periférico. Sendo assim, também acaba por auxiliar no desenvolvimento do processo de re/escritura de que fala Arantes (2015), crucial à remodelação das políticas de visibilidade acerca da diáspora queer, uma vez que o queer se vincula à diáspora nessa "relação privilegiada de transgressividade: ambos são fundamentalmente disruptivos de categorias estáticas do ser, de categorias hegemônicas através das quais subjetividades normativas são produzidas" (THEODORO; COGO, 2018, p. 8).

O segundo ponto se refere ao que, nas palavras de Rancière (2009), equivale a uma "partilha do sensível". Trata-se de um sistema de evidências sensíveis que destaca tanto a existência de um conjunto participativo quanto de inúmeros recortes que nele determinam lugares, partes precisas (RANCIÈRE, 2009). A conceituação proposta pelo 


\section{midiäticales}

autor desloca o ponto de vista da estética apenas como estando a serviço da arte e a transpõe à base da política, a partir da qual é capaz de gerar uma experiência sensível comum. O problema repousa no fato de que toda partilha, todo o "comum", não se estabelece sem que haja zonas excludentes, que acabam por delimitar diferenças entre o pertencente e o preterido.

É isso que se passa com queer-estéticas, ou seja, com as estéticas que estão de algum modo relacionadas aos sujeitos tidos como abjetos, como os sujeitos LGBTIQ+ migrantes. Se por um lado podem expressar uma coesão que une e confere a possibilidade de luta política, de reconhecimento e de exercício de cidadania, por outro atuam como vetores de exclusões, de violências simbólicas e físicas reiteradamente perpetradas, do discurso ao psicológico, da cultura à carne. O sensível não deixa de estar, portanto, condicionado a esses embates constantes para a remodelação do que se considera ou não aceitável no campo dos desejos, das identidades e das expressões de gênero, como o caso de Angel bem exemplifica.

Em suma, nas ambiências midiáticas em que Angel se presentifica, seja mediada por uma narrativa documental ou em suas próprias corporalidades, está colocada a irrefutável complexidade da experiência do sensível. É nessa dimensão que a estética se alicerça, em perspectiva sígnica (enquanto linguagem), comunicacional e política (RANCIÈRE, 2009). A ordem do sensível se converte, por conseguinte, em uma arena de enfrentamentos para a (des)construção de estéticas midiáticas, cujos efeitos nas sociabilidades cotidianas são concretos, principalmente àqueles sujeitos que não se enquadram às suas ordenações hegemônicas. Na diáspora queer, esta aparenta ser a regra.

\section{Referências}

ALENCAR-RODRIGUES, R.; STREY, M. N.; ESPINOSA, L. C. Marcos do gênero nas migrações internacionais das mulheres. Psicologia \& Sociedade, v. 21, n. 3, p. 421430, 2009.

ARANTES, P. Re/escrituras da arte contemporânea: história, arquivo e mídia. Porto Alegre: Sulina, 2015.

BAITELlO, N. A serpente, a maçã e o holograma: esboços para uma teoria da mídia. São Paulo: Paulus, 2010. 


\section{midiätica@e}

BENJAMIN, W. A obra de arte na era de sua reprodutibilidade técnica. In:

Magia e técnica, arte e política. Ensaios sobre literatura e história da cultura. São Paulo: Editora Brasiliense, 1987.

BRASIL, A. Entre o ver e o não ver. O gesto do prestidigitador. In: GUIMARÃES, C.; SOUZA LEAL, B.; MENDONÇA, C. (Orgs.). Comunicação e experiência estética. Belo Horizonte: Editora da UFMG, 2006.

BUTLER, J. Vida precária. Contemporânea, n. 1, p. 13-33, 2011.

Problemas de gênero: feminismo e subversão da identidade. Rio de Janeiro: Civilização Brasileira, 2008.

ELHAJJI, M. Comunicação intercultural: prática social, significado político e abordagem científica. In: E-Compós, v. 6, p. 1-16, 2006.

FELDMAN, I. O apelo realista. In: Revista Famecos, n. 36, p. 61-68, 2008.

FERREIRA, J. P. Cultura das bordas. São Paulo: Ateliê Editorial, 2010.

HALL, S. Pensando a diáspora. Reflexões sobre a terra no exterior. In:

Da diáspora: identidades e mediações culturais. Belo Horizonte: Editora UFMG, 2013. p. 27-55.

KOSMINSKY, E. Questões de gênero em estudos comparativos de imigração: mulheres judias em São Paulo e em Nova York. Cadernos Pagu, n. 23, p. 279-328, 2004.

KRZESLO, E. Migrations et parcours d'exil: les femmes s'imposent. REMHU Revista Interdisciplinar da Mobilidade Humana, Ano XV, n. 29, p. 121-137, 2007.

LOPES, D. Cinema e gênero. In: MASCARELLO, F. História do cinema mundial. Campinas: Papirus, 2006. p. 379-393.

PRECIADO, P. Testo junkie. Sexe, drogue et biopolitique. França: Éditions Grasset \& Fasquelle, 2008.

PRYSTHON, A. Do terceiro cinema ao cinema periférico. Estéticas contemporâneas e cultura mundial. In: Periferia, v. 1, n. 1, p. 79-89, 2009.

RANCIÈRE, J. A partilha do sensível: estética e política. São Paulo: EXO experimental org: Editora 34, 2009.

SILVERSTONE, R. La moral de los medios de comunicación. Sobre el nacimiento de la polis de los medio. Buenos Aires: Amorrotu, 2010.

Por que estudar a mídia? São Paulo: Lyola, 2005.

TEIXEIRA, R. T. Cinema, migração e identidades: representações cinematográficas das identidades brasileiras in between contemporâneas. Intexto, n. 35, p. 76-96, 2016. 


\section{midiäticale}

THEODORO, H. Transgeneridade, mídia e consumo: um estudo de caso das visibilidades midiáticas de Laerte Coutinho. 2016. 156 f. Dissertação (Mestrado em Comunicação e Práticas de Consumo) - Escola Superior de Propaganda e Marketing, São Paulo, 2016.

THEODORO, H.; COGO, D. Da diáspora queer: entre (in)visibilidades sociocomunicacionais e o exercício de cidadania. In: XXVII Encontro Anual da Compós, Pontifícia Universidade Católica de Minas Gerais. Anais... Belo Horizonte, 2018. Disponível

em: <http://www.compos.org.br/data/arquivos_2018/trabalhos_arquivo_DV6WTUDCM8JG VL83E94T_27_6723_25_02_2018_18_38_54.pdf>. Acesso em: ago. 2018.

WESLING, M. Why queer diaspora? Feminist Review, v. 90, issue 1, p. 30-47, 2008. 